\title{
Design of Experimental Platform for the Optimization of Composite Prepreg Tape Lay-Up’s Parameters
}

\author{
Hai-tao Lian \\ State Key Lab of Digital Manufacturing Equipment and \\ Technology \\ Huazhong University of Science and Technology \\ Wuhan, China, 13307198952 \\ lianhaitao0810@126.com
}

\begin{abstract}
The experimental platform designed in this paper can simulate process of the ATL machine, including variable rates and forces the composite prepreg tape laid up. Thanks to the closed loops, the platform is able to ensure the accuracy of the rate and force. As the control unit of the apparatus, PLC has a capacity to deal with signals to meet the needs of the apparatus, such as controlling the rate and the force the prepreg tape laid up and the safety of the platform when wrong operations occur.
\end{abstract}

Keywords-component; PLC; composite prepreg; rate of lay-up; placement force

\section{INTRODUCTION}

With the development of the aviation industry, especially the manufacture of the new generation of big civil aircraft, the composite materials have a rapid advance. Driven by need of higher manufacturing rate and higher quality for aerospace manufacturers, automated lay-up of prepreg has slowly replaced manual lay-up during the production of composite parts. The main methods for automated lay-up are Automated Tape Laying and Automated Fiber Placement. One kind of the ATL machines is shown in Fig.1.

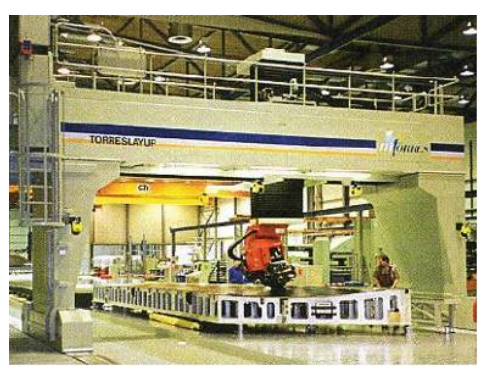

Fig.1 ATL machine in use

\section{RESARCH BACKGROUND}

ATL machines use a continuous spool of composite prepreg and a robotic arm to apply individual plies of prepreg to a pan or substrate in the desired fiber orientations. Equipped with a round application roller, the robotic arm brings the prepreg into contact with the part at some rate and force to accomplish the placement of the composite prepreg.

This project was supported by the National Numerical Control Major Projects (2010ZX04016-013)

\author{
Peng Zhang \\ State Key Lab of Digital Manufacturing Equipment and \\ Technology \\ Huazhong University of Science and Technology \\ Wuhan, China, 15271818960 \\ zphust2005@sina.com.cn
}

In order to ensure the quality of the productions, the composite prepreg must have appropriate tack to prevent shifting, lifting, or sliding of the laid-down prepreg. A number of variables influence the tack of the prepreg and its adherence to an underlying substrate, including the temperature at which the prepreg is laid up, the rate at which the prepreg is laid up and the force at which the prepreg is laid up, etc. So a limited range of tack differences can be accounted for by adjusting the tapelaying machine, controlling the force, the rate and the temperature described above.

In the past, each roll of prepreg would be placed in a tapelaying machine before it could be determined whether or not the parameters are appropriate. Before the lay-up of the parts, we must get the right parameters to ensure the quality of the tape laying, which results waste of the time and money in setting up the tape-laying machine.

We design this experimental platform to simulate the lay-up of the automated tape-laying machine to optimize the rate and the force at which the prepreg is laid up. This allows a manufacturer to test each tack for optimization of the lay-up parameters and control of the prepreg quality prior to using the prepreg in a manufacturing operation.

\section{PLATFORM BUILDING}

\section{A. Structure of the platform}

The platform allows the prepreg to be experienced under conditions similar to those used in a tape-laying machine. This ensures the results of experiments are relevant to the specific application in which the prepreg is to be used.

One embodiment of the platform is able to vary the rate at which the prepreg is laid up. We make use of a servo-motor to drive a spindle to achieve the rectilinear movement. Controlled by the controller and encoder, the serve motor can rotate at variable rates in need.

Another embodiment of the platform is to join composite prepregs under some placement force. Our apparatus comprises a table and a rotatable silicon roller coupled to the table. The roller applies force to the trip of prepreg to join the strip to a table under conditions similar to an automated tape-laying machine. In order to ensure the accuracy of the placement force, we 
use a force sensor and a stepper motor to build up a closed loop control.

Lastly, the apparatus has two limit switches at the end of platform to ensure the safety of the apparatus. The structure of the platform is shown in Fig.2.

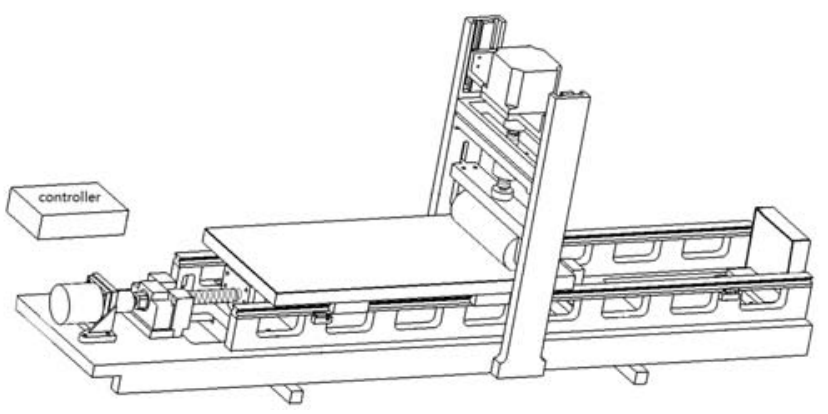

Fig.2 Structure of the platform

\section{B. PLC Control}

The core component of the controller is PLC control. As the brain of the controller, PLC must have capacity to control the variable rates and placement forces at which the prepreg are laid up, and ensure the safety of the platform.

To realize the functions of the movement, we plane the speed control flow chart given in Fig.3.The function of the conversion program is converting the linear speed $(\mathrm{m} / \mathrm{min})$ to pulse frequency $(\mathrm{Hz})$.As shown in Fig.3, the servo-motor and encoder make up a closed loop to ensure the accuracy of the rate.

According to the performance characteristics of servomotor, we must program an appropriate movement pattern, including acceleration movement, constant speed and deceleration movement. So we design a trapezoidal control pattern shown in Fig.4.In PLC, F171 command can meet this need.

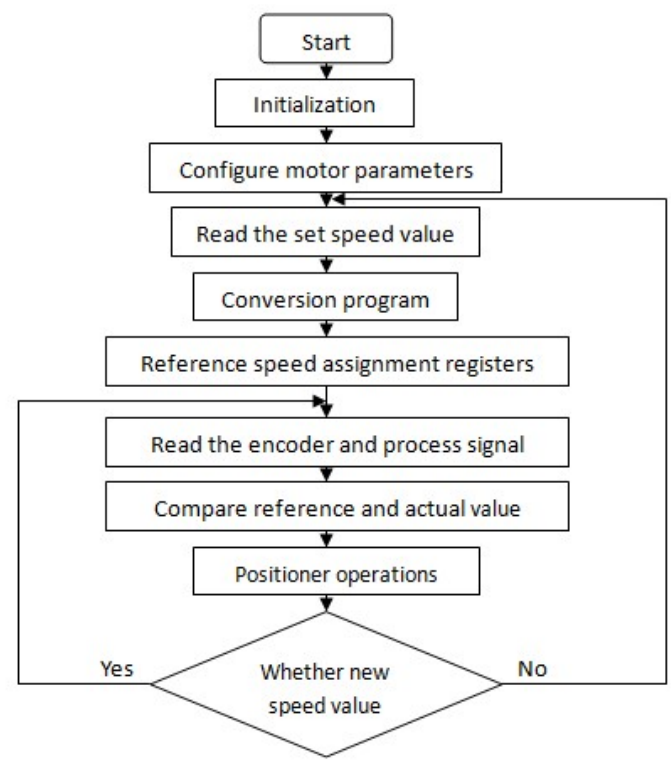

Fig.3 Speed control flow chart

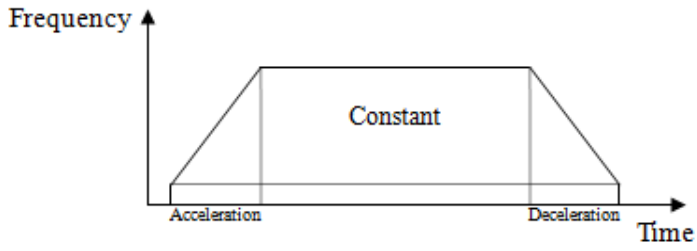

Fig.4 Trapezoidal control pattern of speed

Another embodiment of the platform is to supply the placement force. So we make us of a force sensor and a stepper motor to build a closed loop (Fig.1) to ensure the accuracy of the force. The stepper motor rotates to some angle to drive the crew to press the structure comprised of the rotatable roller and a force sensor by receiving the signals produced by the controler. We design the force control flow chart shown in Fig.5.

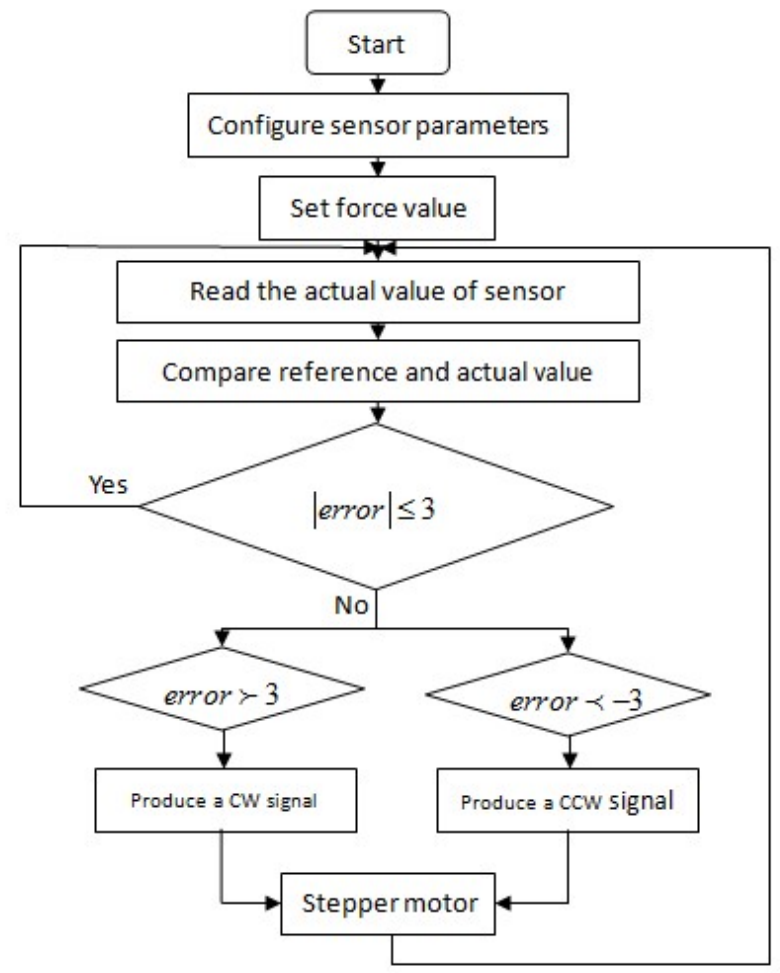

Fig.5 Force control flow chart

The force sensor produces an electric current range of 4$20 \mathrm{~mA}$ through a transmitter at the forces rang of $0-1000 \mathrm{~N}$, while the transfer characteristics of the I/O module is setted 0$20 \mathrm{~mA}$ corresponding 0-4000 data value. So we have to plane a program based on the Eq.1 to deal with relationship of the analog quantity and data.

$$
F_{x}=\frac{\left(W_{x}-W_{x 0}\right) * 1000}{4000-W_{x 0}}
$$

Where: ${ }^{W_{x 0}}=$ the data value when the force is zero

$$
\begin{aligned}
& W_{x}=\text { the data value in real time } \\
& F_{x}=\text { the corresponding force }
\end{aligned}
$$


Special data register DT90052 is designed to operate the counter to reset or forbid counting. Therefore, we can set the value to control the movement of servo-motor to realize the sudden stop of the platform if wrong operations occur in the process of experiments. The program is shown in Fig.6.

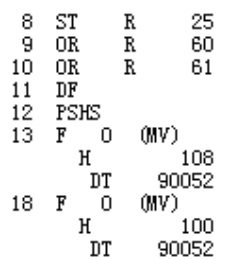

Fig.6 The program of emergency stop

\section{CONCLUSION}

According to the methods discussed above, we build up the experimental platform shown in Fig.7.

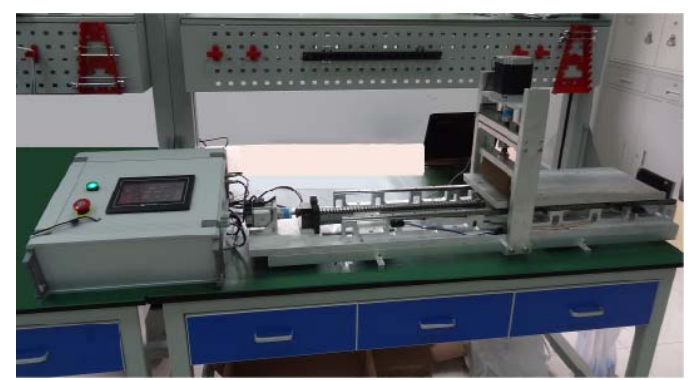

Fig.7 The experimental platform

After the actual test, the experimental platform designed has ability to meet demands used to have an optimization, including variable rates and placement forces at which the prepreg are laid up. Fig.8 shows the difference of the actual speed and designed speed at $1500 \mathrm{r} / \mathrm{min}$. The curve of actual speed fits designed curve very well and the max error in constant area is $17 \mathrm{r}$, nearly one percent of the speed in need. Fig.9 is the placement force error curve diagram of $100 \mathrm{~N}$ in use, the max error in diagram is $\pm 3 \mathrm{~N}$, nearly five percent of the force in need. So, the experimental platform designed is able to ensure the accuracy of the parameters used to be tested.

When wrong operations occur in the process of experiments, the two limit switches has capacity to ensure the safety of the platform.

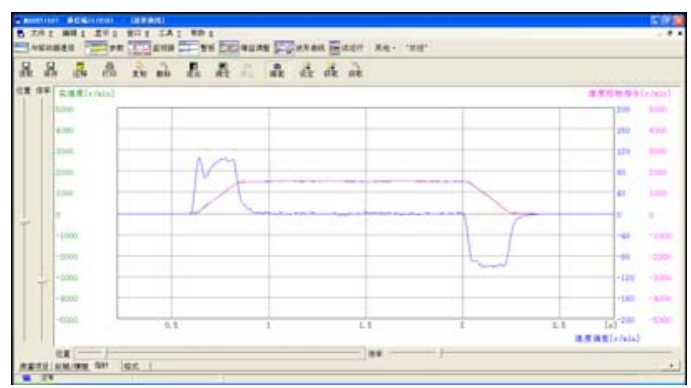

Fig.8 Speed curve diagram

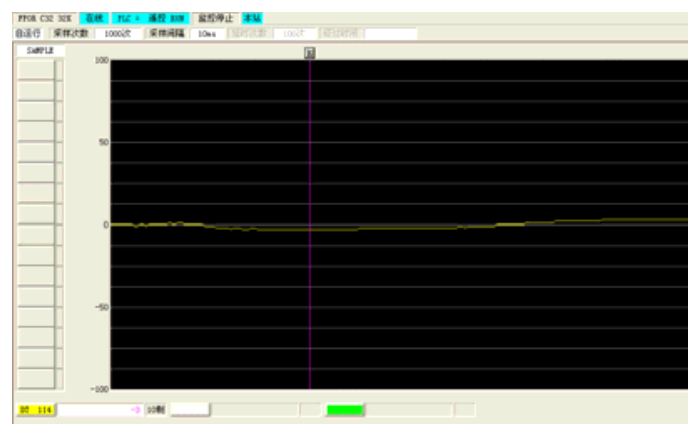

Fig.9 Placement force error curve diagram

The experimental platform is designed to test influences of the parameters during the laying process of prepreg to the quality of the productions. This apparatus has limited capacities to simulate the rates and placement forces at which prepreg are laid up. But, there are a number of variables influencing the tack of the prepreg and its adherence to an underlying substrate. So, it is necessary to develop a newer equipment to study influences of more parameters during lay-up of prepreg to the quailty of the products in the following research.

\section{REFERENCES}

[1] N.Ersoy, T.Garstka, K.Potter, M.R.Wisnom, D.Porter, M.Clegg and G.Stringer.Development of the properties of a carbon fibre reinforced thermosetting composite through cure.Compos.A, Appl.Sci.Mf.2010, 41(3), 401-409.

[2] C.Grant.Automated processes for composite air-craft structure.Ind.robot.2006, 33(2), 117-121.

[3] R.J.Crossley, P.J.Schubel and N.A.Warrior.The experimental determination of prepreg tack and dynamic stiffness. Composites Part A: Applied Science and Manufacturing.2012, 43(3), 423-434.

[4] R.O.Buckingham*, G.C.Newell.Automating the manufacture of composite broadgoods. Composites Part A: Applied Science and Manufacturing.1996, 27(3), 191-200.

[5] Jun-wei Qi, An-ran Li, Zhi-jun Huang, Wen-lei Xiong. Research on the tape laying technologic parameters.FRP/CM, 2011, 4:46-51(in Chinese).

[6] A. Mills*.Automation of carbon fibre preform manufacture for affordable aerospace applications. Composites Part A: Applied Science and Manufacturing.2001, 32(7), 955-962.

[7] Chen-xi Wu, Rong Jiang.Design of position control system based on PLC-Servo driving. Manufacturing automation.2008, 30(4), 84-86(in Chinese).

[8] Panasonic. The Panasonic MINAS A5 Series AC servo motor drive instruction manual.2009 (in Chinese).

[9] Panasonic. FP Series PLC Programming Manual.2009 (in Chinese). 